\title{
Methodical approach to the substantiation of alternative modules for managing the development of territorial production complexes
}

\author{
Ariadna Kirillova and Anna Belyakova* \\ Moscow State University of Civil Engineering, Yaroslavskoe shosse, 26, Moscow, 129337, Russia
}

\begin{abstract}
Sustainable innovative development of territorially production complexes (TPC) is viewed as a single modular system based on a multifactor analysis of alternatives, ensuring a balance of interests of all subjects of investment, construction and production activities, can be ensured by the use of an improved mechanism for selecting alternatives in The reorganization and project management of industrial renewal projects. The carried out analysis of the evolution of program-target models of urban TPC development showed the existence of a stable trend of shifting the targets towards innovative development that form production chains of the full cycle. Typical characteristics of urban TIC that affect the development and implementation of integrated reorganization projects are singled out. It is proposed that existing urban TPC, subject to reorganization, be considered in the context of the theory of poles (points) of growth of Fr. Perru in view of the correspondence of their key characteristics (geographic location, availability of existing production infrastructure, etc.) The proposed approach to the justification of alternative management modules for the development of the TPC is formalized in the form of the objective function of the Pareto multicriterion optimum of multidirectional private target parameters reflecting various types of efficiency of the project solution compliance with critical constraints.
\end{abstract}

\section{Introduction}

At present, the sustainable innovative development of large cities and their transformation into innovation and production centers with the formation of a quality multifunctional urban environment in order to increase the competitiveness of urban economic systems and the production potential of cities is hampered by the lack of free development sites in the territories where existing significant and promising projects of industrial development, aimed at solving existing and rotation potential problems of large cities [1-3].

In these conditions, the attention of the subjects of town-planning activity is concentrated in the territories of industrial enterprises that currently operate inefficiently or practically do not function within the boundaries of large cities $[4,5]$.

* Corresponding author: ann.kudashkina@gmail.com 
At the same time, the issue of the development of industrial zones is paid special attention to the city authorities in Moscow, St. Petersburg, Novosibirsk, Ekaterinburg, Nizhny Novgorod, Samara, Omsk, Kazan, Chelyabinsk, Rostov-on-Don, Ufa, Volgograd and Krasnoyarsk and other large cities of Russia [6-9].

The solution of the urgent problems of urban development requires reforming approaches to the management of production areas within the existing urban development, their development on an innovative basis, high-tech re-industrialization, modernization of existing production facilities, which corresponds to foreign experience, the formation of local innovative production centers integrated into the urban environment [10-12].

Under Russian conditions, a successful basis for the sustainable development of urban territorial production complexes (TPC) is the currently successfully implemented in more than 50 regions of the Russian Federation and an actively stimulated system for the creation of industrial parks (IP) and technology parks, forming centers of concentration of subjects of innovation and production activity and objects of industrial and scientific and technological infrastructure [8, 13-15].

\section{Materials and Methods}

The analysis of the evolution of program and target models of development and renewal urban TPC, implemented by the state, showed the presence of a steady trend of displacement of targets towards innovative development of high-tech re-industrialization, modernization of existing production facilities and localization companies, forming a production chains of full cycle .

Urban TPC often have typical characteristics and have, as a rule, identical encumbrances. From the perspective of the most likely nature of the impact on the development and implementation of projects of complex reorganization, they can be divided as follows:

- Positive: good location, considerable area, availability of utilities;

- Ambiguous: the availability of buildings and structures of various functional purposes (with atypical architectural and constructive solutions);

- Negative: poor environmental conditions, underdeveloped transport infrastructure, depreciation of fixed assets, legal encumbrances.

Considered urban TPC, subject to reorganization, it is expedient to consider in the context of the theory of poles (points) of growth of Fr. Perru (fr. François Perroux), in view of the correspondence of their key characteristics (geographic location, availability of the existing production infrastructure, etc.) to the main criteria that determine the optimal zones for locating local "foci" of territorial development.

The formation of growth points presupposes the territorial concentration and synergy of entrepreneurial, innovative, industrial, investment and other types of infrastructure and corresponds to the cluster strategy of economic development.

The concept of a project for the reorganization of an industrial area should be formed based on a specific urban development situation and taking into account the set of real characteristics of the territory under consideration. Two most significant aspects should be identified: the definition of the future functional purpose of the territory (preservation of the production function, full or partial re-functionalization) and the degree of use of existing buildings and structures on the territory.

On the basis of the classification of the main types of design solutions, a matrix of variants of the concept of the development of urban TPK was developed (Figure 1), which allows the management entities in the planning procedures to analyze the conditions and 
prerequisites reflecting the socio-economic, urban and other conditions of the territory in question, condition of the transformed production, to make a choice of conceptual solutions that ensure the maximum effectiveness of the TPC development project, including with formation of the industrial parks.

Depending on the homogeneity of the TPK under consideration, as well as the extent to which its territory is used in the production process, it may be concluded that a development concept combining several elements of a variant matrix can be made as a result of the analysis.

The proposed methodological approach to the justification of alternative control modules for the development of the TPK is formalized in the form of the objective function of the Pareto multicriteria optimum of multidirectional target parameters subject to the observance of critical limitations:

$$
Y_{\text {opt }}=o p t\left(\begin{array}{c}
E_{\text {econ }}(x) ; E_{\text {budg }}(x) ; E_{u r b}(x) ; E_{\text {soc }}(x) ; \\
\left.E_{\text {prod }}(x) ; E_{\text {tech }}(x) ; E_{\text {inn }}(x)\right) \rightarrow \max
\end{array}\right),
$$

where:

$Y_{o p t}$ - optimal choice of alternative control modules for the development of the TPC;

$\mathrm{x}$ - private alternative solution of the TPC development project, characterized by a set of technical and economic indicators;

$\mathrm{E}$ - private optimization targets, which are proposed to use indicators reflecting various types of efficiency of the project solution x (economic $E_{\text {econ }}(x)$, commercial $E_{\text {comm }}(x)$, budgetary $E_{\text {budg }}(x)$, town-planning (urbanization) $E_{\text {urb }}(x)$, social $E_{\text {soc }}(x)$, production $E_{\text {prod }}(x)$, technological $E_{\text {tech }}(x)$, innovative $E_{\text {inn }}(x)$ ).

\begin{tabular}{|c|c|c|c|c|c|c|}
\hline & \multirow[b]{2}{*}{ Main prerequisites / conditions } & \multirow{2}{*}{$\begin{array}{l}\text { Preservation of } \\
\text { TPC }\end{array}$} & \multicolumn{3}{|c|}{ Variants of the concept of reorganization of the TPC } & \multirow{2}{*}{$\begin{array}{c}\text { Preservation and } \\
\text { development of } \\
\text { existing production }\end{array}$} \\
\hline & & & $\begin{array}{c}\text { Redevelopment } \\
\text { (liquidation) }\end{array}$ & Re-profiling & $\begin{array}{l}\text { Reconstruction } \\
\text { and renewal of } \\
\text { fixed assets }\end{array}$ & \\
\hline \multirow{2}{*}{ 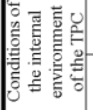 } & Commercial potential of current production & - & - & - & + & + \\
\hline & High level of depreciation of fixed assets & - & + & $\cdot$ & t & - \\
\hline \multirow{3}{*}{ 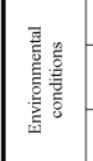 } & Production potential of the territory & - & - & - & + & + \\
\hline & $\begin{array}{c}\text { Градостроптельный потенщиал } \\
\text { территорил }\end{array}$ & - & + & + & - & - \\
\hline & Town-planning potential of the territory & - & - & + & + & + \\
\hline \multicolumn{7}{|c|}{ Critical conditions: } \\
\hline & Investment potential & - & \multicolumn{3}{|c|}{+} & - \\
\hline & Environmental Safety & - & \multicolumn{3}{|c|}{+} & + \\
\hline
\end{tabular}

conditions are provided

conditions are not provided

Fig. 1. Matrix of options of conceptual directions of development of urban TPC

\section{Results}

The organizational and economic mechanism for managing the TPC reorganization project with the formation of the infrastructure of IP and technology parks ensures the 
implementation of key management functions at all stages of the life cycle of the project through the use of improved methodological tools. The key stage in the implementation of the TPC reorganization project is the stage of the project implementation concept development, presented by the developed algorithm, including factor analysis of TPK characteristics, modeling of alternative development modules, concept formation including the development of the design specification (Figure 2).

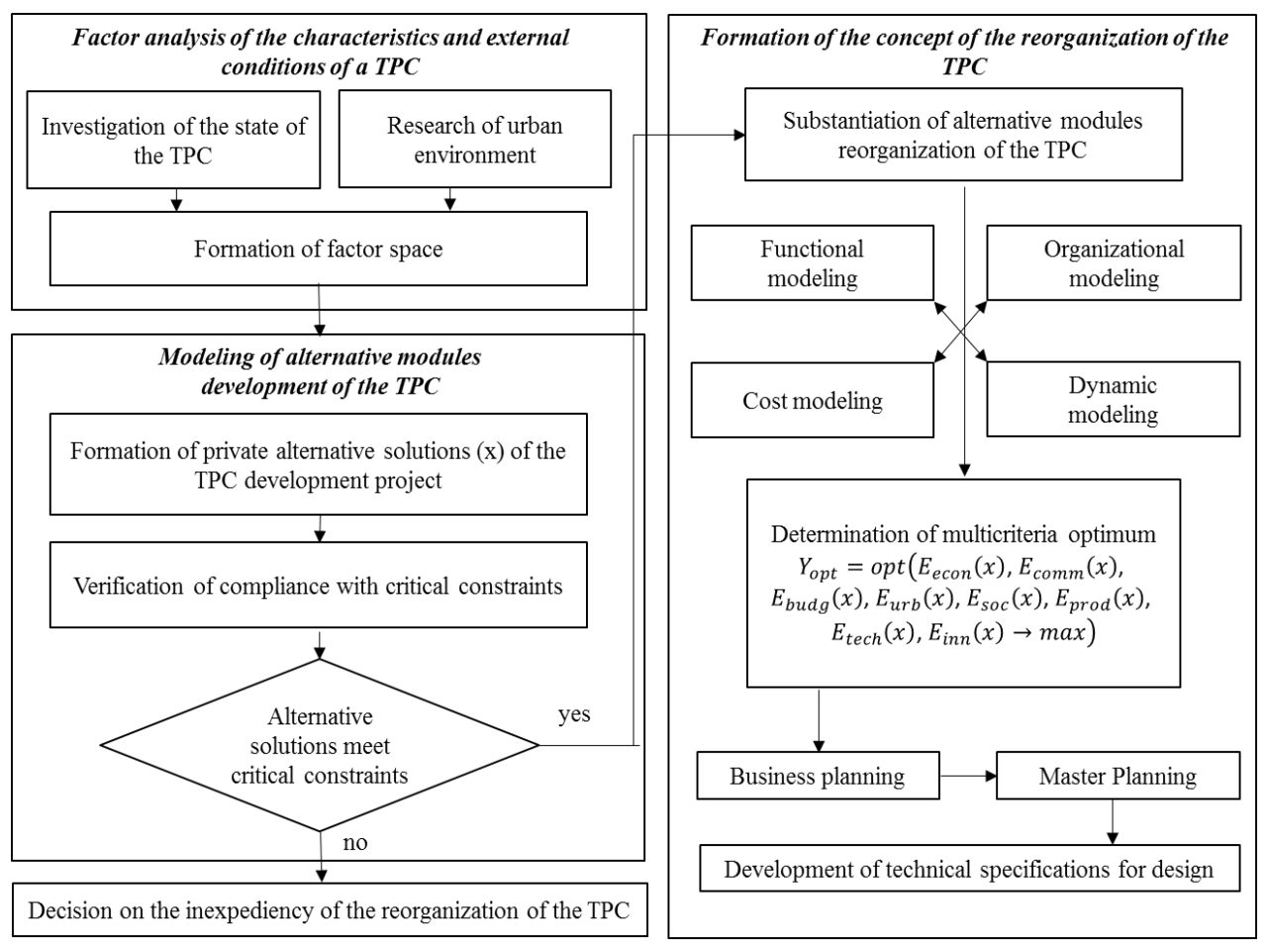

Fig. 2. Algorithm for the formation of alternative modules for the selection of the concept for the implementation of the reorganization of territorial production complexes

\section{Conclusions}

Conducting a comprehensive reorganization of production zones contributes to the provision of the city with additional jobs, the construction of technology parks, the development of infrastructure, the formation of a quality urban environment and increased investment attractiveness of the surrounding buildings.

\section{References}

1. M. Benoit, C. Patsias, Journal of Rural Studies, 55, 1-11 (2017)

2. P. Xie, Annals of Tourism Research, 55, 141-154 (2015)

3. V. V. Zuyev, S. L. Bondarenko, D. A. Savchuk, A. Yu. Bocharov, 30, 242-245 (2009)

4. B. Domański, International Encyclopedia of Human Geography, 1, 190-195 (2009)

5. J. Cerceau, N. Mat, G. Junqua, Geoforum, 89, 29-4, (2018)

6. P. Zamora, R. Cobos, C. Huerta, Geoforum, 87, 48-61 (2017) 
7. M. Rasmussen, C. Lund, World Development, 101, 388-399 (2018)

8. A. Belyakova, Real estate: economics, management, 4, 14-16 (2015)

9. A. Tatarkin, Education and Science, 90, 26-45 (2012)

10. A.Evseenko, K.Ogryzko, Problems and prospects of modernization of the Russian economy, (Institute of Economics and Industrial Engineering of the SB RAS, Novosibirsk, 2014)

11. V. Zhigalov, N.Aparin, Transport business in Russia, 12-4, 79-81 (2006)

12. R. Mammaev, A. Shlafman, Scientific and technical lists of the St. Petersburg State Polytechnic University. Economic sciences, 75, 88-94 (2009)

13. V. Rykov, E.Dubinina, Formation and management of production complexes - basis for effective use of fixed funds, (The Baikal state. University of Economics and Law. Irkutsk, 2009)

14. M.Aristarkhova, T.Matyagina, Yu.Poroshin, Managerial Accounting and Finance, 2, 90-108 (2008)

15. I. Shogenova, M. Abitova, Izvestiya of the Kabardino-Balkarian Science Center of the Russian Academy of Sciences, 38, 163-166 (2010) 